\title{
Kanser Hastalarında ABO ve Rhesus Kan Gruplarının Dağılımı
}

\author{
Fatih İNCI, Fatih KARATAŞ
}

Karabük Üniversitesi Tıp Fakültesi İç Hastalıkları ve Tıbbi Onkoloji Anabilim Dalı, Karabük.

\begin{abstract}
ÖZET
Literatürde $\mathrm{ABO}$ ve Rhesus (Rh) kan gruplarının kanser hastalığı ile ilişkisine dair yapılan çalışmalar incelendiğinde mutlak bir sonuç çıkarmak mümkün olmamakta, sonuçlar ülkelere ve çalışmanın yapıldığı merkezlere göre değişkenlik gösterebilmektedir. Bu çalışmanın amacı kliniğimizde ABO-Rh kan gruplarının kanser alt tiplerine göre dağılımını değerlendirmektir. Ocak 2015- Ocak 2020 tarihleri arasında Tıbbi Onkoloji kliniğinde kanser tanısıyla takip ve tedavi edilen hastaların kan gruplarının kanser tiplerine göre dağılımı incelendi ve veriler kanser olmayan kontrol grubu ile karşılaştırıldı. Katılımcıların yaş, cinsiyet gibi sosyodemografik verileri, kanser alt tipi ve kan grupları (ABO-Rh) retrospektif olarak hasta dosyası ve hastane otomasyon sisteminden tarandı. Çalışmaya 1894'ü (\%22.1) kanser hastası, 6681'i (\%77.9) kontrol grubu olmak üzere 8575 birey dahil edildi. Kontrol grubu ve kanser hastalarında kan gruplarının dağılımında istatistiksel olarak anlamlı farklılık saptandı ( $\mathrm{p}<0.001$ ). Malign melanom, böbrek, kolorektal, meme, over kanserlerinde ARh $(+)$ kan grubu; pankreas kanserinde ise $\mathrm{ORh}(+)$ kan grubu anlamlı derecede yüksek oranda saptandı. Diğer kanser tiplerinde kan grupları açısından bir farklılık tespit edilmedi. Çok değişkenli lojistik regresyon analizine göre; A ve O kan grupları ve ileri yaşın kanser hastalığı için bağımsız prediktif faktörler olduğu belirlendi. Kanser hastaları ve kontrol grubunda ABO-Rh kan gruplarının dağılımının farklı olduğu görüldü. Kanser alt tipleri incelendiğinde pankreas kanserinde $\mathrm{O}$ kan grubunun, malign melanom ve böbrek tümörlerde ise A kan grubunun daha yüksek oranda olduğu görüldü. Sağlıklı kişilere göre ileri yaş, A ve O kan gruplarının kanser hastalığı için bağımsız prediktif faktörler olduğu görüldü.
\end{abstract}

Anahtar Kelimeler: ABO. Rh. Kan grubu. Kanser. Risk.

Distribution of ABO and Rhesus Blood Groups in Cancer Patients

\begin{abstract}
ABSRACT
When studies on the relation of $\mathrm{ABO}$ and Rhesus $(\mathrm{Rh})$ blood groups with cancer are examined in the literature, it is not possible to draw an absolute conclusion, the results may vary according to the countries and centers where the study was conducted. The aim of this study is to evaluate the distribution of ABO-Rh blood groups according to cancer subtypes in our clinic. The distribution of blood groups of patients who were followed up for cancer between January 2015 and 2020 according to their cancer types was examined and the data were compared with the non-cancer control group. Participants' sociodemographic data such as age and gender, cancer type and blood groups (ABO-Rh) were retrospectively scanned from the hospital automation system. The study included 1894 (22.1\%) cancer patients and 6681 (77.9\%) control group. There was a statistically significant difference in blood groups of control group and cancer patients $(\mathrm{p}<0.001)$. ARh $(+)$ blood group in melanoma, renal, colorectal, breast and ovarian cancers; ORh $(+)$ blood group was found with a significantly higher rate in pancreatic cancer. In multivariate regression analysis, being group $\mathrm{A}$ and group $\mathrm{O}$ and increasing age were found to be independent predictive factors for cancer. It was observed that the distribution of ABO-Rh blood groups was different in the control group and cancer patients. In cancer subtypes, the rate of $\mathrm{O}$ blood group in pancreatic cancer and A blood group in melanoma and renal cell tumors were found to be higher. According to healthy people, advanced age, A and O blood groups were found to be independent risk factors for cancer diagnosis.
\end{abstract}

Key Words: ABO. Rh. Blood group. Cancer. Risk.

Geliş Tarihi: 18.Ekim.2020

Kabul Tarihi: 03.Aralık.2020

Dr. Fatih İNCi

Karabük Üniversitesi Tıp Fakültesi,

İç Hastalıkları ve Tıbbi Onkoloji Anabilim Dalı,

Karabük.

Tel: 05387629686

E-posta: fatihinci65@hotmail.com

Yazarların ORCID ID Bilgisi:

Fatih INCi: 0000-0002-7590-7630

Fatih KARATAŞ: 0000-0003-4022-7923
Kanser, gelişmiş ülkelerde önde gelen ölüm nedenleri arasında yer almaktadır ${ }^{1}$. ABO ve Rhesus (Rh) kan gruplarının kanser biyolojisindeki rolü çeşitli araştırmacılar tarafindan incelenmiştir. ABO kan grubu antijenleri, eritrosit zarında ve diğer birçok hücre yüzeyinde eksprese edilir. ABO kan grupları ile kanser arasındaki patofizyoloji incelendiğinde, immün cevapta hücre membranı kaynaklı sinyal oluşumundan sorumlu olan Glycosiltransferase A ve Glycosiltransferase B'deki enzimatik aktivitesindeki düzensizlikler, serum Von Willebrand faktör seviyelerinin plazma modülasyonuna sebep olarak, anjiogenez ve tümör 


\section{F. İnci ve F. Karataş}

oluşumuna neden olmaktadır. ABO antijenleri ile hücreler arası adezyon molekülleri arasındaki ilişkinin tümör başlangıcı ve ilerlemesinde etkili olduğu bildirilmiştir ${ }^{2}$. Kan gruplarının 1901 yılında Karl Landsteiner tarafindan keşfinden ve 1953 tarihinde Aird tarafindan A kan grubunun mide kanserinde rol oynadığ1nı deklare etmesinden sonra birçok kanser türünde kan grupları araştırma konusu olmuştur ${ }^{3}$. ABO kan grubu genleri, birçok kanserde genetik değişikliğin yaygın olduğu 9q34.2 bölgesinde haritalanır. Bu nedenle, kan grubu antijen ekspresyonu, tümörün genetik değişiminden etkilenebilir. Önceki çalışmalar, ABO kan grubu ile pankreas kanseri ve mide kanseri dahil olmak üzere bazı epitelyal kanserler arasında olası bir ilişki olduğunu göstermektedir. ABO kan grupları ve kanser riski arasında gözlenen ilişkiyi açıklamak için enflamatuvar değişiklikler, hücreler arası adezyon ve membran sinyalindeki değişiklikler dahil olmak üzere çeşitli mekanizmalar öne sürülmüştür ${ }^{4}$. Bu durum kan grubu antijeni ile çeşitli kanser tipleri arasında potansiyel korelasyon olabileceğini düşündürmektedir ${ }^{5}$. Bununla birlikte, ABO kan grubu tipleri ve kanser riski arasındaki ilişkinin kesin olmadığı bildirilmiştir ${ }^{6}$.

$\mathrm{Bu}$ çalışmada, klinikte pratik şekilde ulaşılabilen ABO-Rh kan gruplarının kanser hastalığı ve alt tiplerine göre dağılımını değerlendirmeyi amaçladık.

\section{Gereç ve Yöntem}

Ocak 2015- Ocak 2020 tarihleri arasında bir üniversitesi hastanesi Tıbbi Onkoloji kliniğinde kanser nedeni ile takip ve tedavi edilen hastaların kan gruplarının kanser tiplerine göre dağılımı kanser olmayan bireylerle karşılaştırıldı. Katılımcıların yaş, cinsiyet gibi sosyodemografik verileri, kanser tipi ve kan grupları (ABO-Rh), retrospektif olarak hasta dosyası ve hasta- ne otomasyon sisteminden tarandı. Veri kaydı eksik olanlar, sosyodemografik kayıtlarına ulaşılamayanlar çalışma dışı bırakıldı.

Çalışmaya dahil edilme kriterleri, 18 yaşından büyük olmak, kanser hastaları için patolojik olarak kanıtlanmış kanser hastalığına sahip olmak ve tüm katılımcılar için kan grubu verilerine sahip olmak olarak belirlendi.

Çalışma için Karabük Üniversitesi Girişimsel Olmayan Klinik Araştırmalar Etik Kurulu'ndan onay alındı (09.06.2020 tarih ve 2020/250 sayılı karar).

\section{Istatistiksel Analiz}

Verilerin istatistiksel analizi için SPSS 22.0 programı kullanıldı. Veriler ortalama \pm standart sapma ve yüzde olarak hesaplandı. Kanser türleri ile kan grupları arasındaki ilişkiyi araştırmak için ki-kare testi kullanıldı. Kanser gelişimi için prediktif olabilecek parametrelerde lojistik regresyon analizi yapıldı. $\mathrm{p}<0.05$ değerleri istatistiksel olarak anlamlı kabul edildi.

\section{Bulgular}

Çalışmaya 8575 birey dahil edildi. Bireylerin 1894'ü (\%22.1) kanser hastas1, 6681'i (\%77.9) kontrol grubundan oluşmaktaydı. Yaş ortalaması 41.2 yıl olarak tespit edildi (min 18- $\max 92$ ). Bireylerin \%50.1'i erkek, \%49.9'u kadındı. Kanser hastalarının 1004'ü (\%53) erkek, 890’1 (\%47) kadındı.

Çalışmaya dahil edilen bireylerden A kan grubunda 3829 (\%44.7), B kan grubunda 1364 (\%15.9), O kan grubunda 2154 (\%25.1), AB kan grubunda 1228 (\%14.3) kişi vardı. Sırasıyla tüm bireylerdeki kan grubu dağılımları $\mathrm{A}>\mathrm{O}>\mathrm{B}>\mathrm{AB}$ şeklindeydi. Tüm bireylerde ABO-Rh kan grubu dağılımı A $\mathrm{Rh}(+)$ $(\% 40.4)>\mathrm{O}$ Rh $(+)(\% 22.2)>\mathrm{B}$ Rh $(+)(\% 13.9)>\mathrm{AB}$

Tablo I. Kanser alt tipleri ve kontrol grubunun ABO Rh gruplarına göre dağılımı

\begin{tabular}{|c|c|c|c|c|c|c|c|c|c|c|}
\hline Değişkenler & $\begin{array}{c}\text { ABRh(-) } \\
n(\%)\end{array}$ & $\begin{array}{c}\mathrm{ABRh}(+) \\
\mathrm{n}(\%)\end{array}$ & $\begin{array}{c}\operatorname{ARh}(-) \\
n(\%)\end{array}$ & $\begin{array}{c}\mathrm{ARh}(+) \\
\mathrm{n}(\%)\end{array}$ & $\begin{array}{c}\mathrm{BRh}(-) \\
\mathrm{n}(\%)\end{array}$ & $\begin{array}{c}\mathrm{BRh}(+) \\
\mathrm{n}(\%)\end{array}$ & $\begin{array}{l}\text { ORh(-) } \\
\mathrm{n}(\%)\end{array}$ & $\begin{array}{c}\mathrm{ORh}(+) \\
\mathrm{n}(\%)\end{array}$ & $\begin{array}{c}\text { Total } \\
n\end{array}$ & $p$ \\
\hline Kontrol & $57(0.9)$ & 1019(15.3) & $294(4.4)$ & $2637(39.5)$ & $138(2.1)$ & 968(14.5) & $175(2.6)$ & 1393(20.9) & 6681 & \multirow[t]{2}{*}{0.000} \\
\hline Kanser & $30(1.6)$ & $122(6.4)$ & $72(3.8)$ & $826(43.6)$ & $37(2.0)$ & 221(11.7) & $76(4.0)$ & $510(26.9)$ & 1894 & \\
\hline Akciğer & $4(1.5)$ & $17(6.3)$ & $13(4.9)$ & $113(42.2)$ & $6(2.2)$ & $29(10.8)$ & 15(5.6) & $71(26.5)$ & 268 & 0.849 \\
\hline Nazofareks & $0(0)$ & $6(13.6)$ & 2(4.5) & $22(50)$ & $0(0)$ & $3(6.8)$ & $2(4.5)$ & $9(20.5)$ & 44 & 0.394 \\
\hline Beyin & $0(0)$ & $6(12.5)$ & $0(0)$ & $17(35.4)$ & $0(0)$ & 9(18.8) & $0(0)$ & $16(33.3)$ & 48 & 0.100 \\
\hline Böbrek & $0(0)$ & $0(0)$ & $0(0)$ & $50(68.5)$ & $2(2.7)$ & $4(5.5)$ & $2(2.7)$ & $15(20.5)$ & 73 & 0.001 \\
\hline Melanom & $0(0)$ & $2(4.5)$ & $0(0)$ & $17(38.6)$ & $6(13.6)$ & $7(15.9)$ & $0(0)$ & 12(27.3) & 44 & 0.000 \\
\hline Uterus & 2(5.4) & $4(10.8)$ & $2(5.4)$ & $16(43.2)$ & $0(0)$ & 2(5.4) & $0(0)$ & 11(29.7) & 37 & 0.292 \\
\hline Kan & 2(3) & $5(7.5)$ & $3(4.5)$ & $22(32.8)$ & 2(3) & 9(13.4) & $4(6)$ & $20(29.9)$ & 67 & 0.738 \\
\hline Kolorektal & $4(1.1)$ & $22(6.0)$ & $20(5.4)$ & $156(42.3)$ & $5(1.4)$ & 53(14.4) & $6(1.6)$ & 103(27.9) & 369 & 0.042 \\
\hline Meme & $13(3.8)$ & $14(4.1)$ & $9(2.6)$ & $150(43.9)$ & $7(2.0)$ & 52(15.2) & $8(2.3)$ & $89(26.0)$ & 342 & 0.001 \\
\hline Mesane & $0(0)$ & $6(9.4)$ & $4(6.3)$ & $31(48.4)$ & $0(0.0)$ & $6(9.4)$ & $5(7.8)$ & 12(18.8) & 64 & 0.256 \\
\hline Mide & $0(0.0)$ & $15(8.1)$ & $5(2.7)$ & $88(47.6)$ & $6(3.2)$ & $11(5.9)$ & $8(4.3)$ & 52(28.1) & 185 & 0.068 \\
\hline Over & $0(0.0)$ & 2(4.3) & $4(8.5)$ & $20(42.6)$ & $0(0.0)$ & $6(12.8)$ & $6(12.8)$ & 9(19.1) & 47 & 0.033 \\
\hline Özofagus & $1(7.7)$ & 2(15.4) & $0(0)$ & $5(38.5)$ & $0(0)$ & 2(15.4) & $0(0)$ & $3(23.1)$ & 13 & 0.506 \\
\hline Pankreas & $0(0)$ & 7(11.5) & $0(0)$ & $20(32.8)$ & $0(0)$ & $5(8.2)$ & $7(11.5)$ & 22(36.1) & 61 & 0,005 \\
\hline Prostat & 2(1.7) & $5(4.2)$ & $5(4.2)$ & $55(45.8)$ & $3(2.5)$ & 14(11.7) & $8(6.7)$ & $28(23.3)$ & 120 & 0.747 \\
\hline SafraYolları & 2(5.7) & $1(2.9)$ & $3(8.6)$ & 13(37.1) & $0(0)$ & 4(11.4) & $4(11.4)$ & $8(22.9)$ & 35 & 0.076 \\
\hline Sarkom & $0(0.0)$ & $5(10.6)$ & $2(4.3)$ & $15(31.9)$ & $0(0.0)$ & $5(10.6)$ & $0(0.0)$ & $20(42.6)$ & 47 & 0.143 \\
\hline Testis & $0(0.0)$ & $3(10.0)$ & $0(0.0)$ & $16(53.3)$ & $0(0.0)$ & $0(0.0)$ & $1(3.3)$ & $10(33.3)$ & 30 & 0.374 \\
\hline
\end{tabular}




\section{Kan Grubu ve Kanser İliş̧kisi}

Rh (+) (\%13.3)> A Rh (-) (\%4.3)> O Rh (-) (\%2.9)> B Rh (-) (\%2.0)> AB Rh (-) (\%1) olarak belirlendi. Kanser hastalarındaki ABO-Rh kan grubu dağılım ise A Rh (+) (\%43.6)> O Rh (+) (\%26.9)> B Rh (+) $(\% 11.7)>\mathrm{AB}$ Rh $(+)(\% 6.4)>\mathrm{O} \mathrm{Rh}(-)(\% 4.0)>\mathrm{A}$ $\mathrm{Rh}(-)$ (\%3.8)> B Rh (-) (\%2.0)> AB Rh (-) (\%1.6) şeklindeydi. Kontrol grubunun $\mathrm{ABO}-\mathrm{Rh}$ kan grubu dağılımı sıklık sırasına göre A Rh (+) (\%39.5), O Rh (+) (\%20.9), AB Rh (+) (\%15.3), B Rh (+) (\%14.5), A Rh (-) (\%4.4), O Rh (-) (\%2.6), B Rh (-) (\%2.1), AB Rh (-) (\%0.9) şeklindeydi. Kanser hastaları ve kontrol grubu arasında ABO-Rh kan grubu dağılımına bakıldığında istatistiksel anlamlı farkın olduğu görüldü (p $<0.001$ ) (Tablo I). Bu farklılık gruplar arasında $\mathrm{Rh}$ faktörü dikkate alınmadan yalnızca ABO kan grupları incelendiğinde de saptanmıştır $(\mathrm{p}<0.001)$ (Tablo II).

Tablo II: Kanser grubu ve kontrol grubu arasinda $\mathrm{ABO}$ grupları fark1

\begin{tabular}{|l|l|l|l|l|c|}
\hline Değişkenler & $\begin{array}{c}\text { Kanser } n \\
(\%)\end{array}$ & Kontrol $n(\%)$ & OR & Cl & $p$ \\
\hline$A$ & $898(47.4)$ & $2931(43.9)$ & 1.154 & $1.041-1.278$ & 0.006 \\
\hline$B$ & $258(13.7)$ & $1106(16.6)$ & 0.798 & $0.690-0.924$ & 0.002 \\
\hline$O$ & $586(30.9)$ & $1568(23.4)$ & 1.457 & $1.302-1.631$ & 0.000 \\
\hline$A B$ & $152(8)$ & $1076(16.1)$ & 0.455 & $0.380-0.543$ & 0.000 \\
\hline$p$, ki-kare testi; $n$, sayl; OR, Odds Ratio; Cl, Confidence Interval \\
\hline
\end{tabular}

Kanser alt tipleri arasında, ABO-Rh kan gruplarının hem cinsiyet ayırımı yapılarak hem de ayırım yapılmadan dağılımı değerlendirildiğinde anlamlı farklılık olduğu görüldü ( $\mathrm{p}<0.001)$ (Tablo III).

Tüm grupta 917 (\%10.7) Rh (-), 7658 (\%89,3) Rh (+) birey vardı. Kanser hastaları ve kontrol grubu arasında farkl1l1k $(\mathrm{p}=0.294)$ tespit edilemedi.

Kanser hastalarının alt tiplerine bakıldığında 268 (\%3.1) akciğer, $44(\% 0.5)$ baş boyun tümörü, 48 (\%0.6) beyin tümörü, $73(\% 0.9)$ böbrek tümörü, 44 (\%0.5) malign melanom, 37 (\%0.4) endometrium kanseri, 67 (\%0.8) hematolojik malignite, 369 (\%4.3) kolorektal kanser, 342 (\%4) meme kanseri, 64 (\%0.7) mesane kanseri, 185 (\%2.2) mide kanseri, 47 (\%0.5) over kanseri, 13 (\%0.2) özofagus tümörü, 61 (\%0.7) pankreas kanseri, 120 (\%1.4) prostat kanseri, 35 $(\% 0.4)$ safra yolları tümörü, $47(\% 0.5)$ sarkom grubu tümör, 30 (\%0.3) testis tümörü içermekteydi.

Kanser tiplerine göre kan grupları incelendiğinde, A Rh (+) kan grubu malign melanom ( $\mathrm{p}=0.001)$, böbrek tümörü ( $p<0.001)$, kolorektal kanserler $(\mathrm{p}=0.042)$, meme kanseri $(p=0.001)$, over kanserinde $(p=0.033)$, $\mathrm{O} \mathrm{Rh}(+)$ kan grubu ise pankreas kanserinde $(\mathrm{p}=0.005)$ anlamlı derecede yüksek oranda saptandı.

Çok değişkenli lojistik regresyon analizinde A kan grubu (OR, 2.415; \%95 CI: 1.869-3.120, p <0.001) ve

Tablo III: Kanser alt tiplerinin ABO RH ve cinsiyete göre dağılımı

\begin{tabular}{|c|c|c|c|c|c|c|c|c|c|c|c|}
\hline Değişkenler & Cinsiyet & $\begin{array}{c}\text { AB Rh(-) } \\
n(\%)\end{array}$ & $\begin{array}{c}\mathrm{AB} \\
\mathrm{Rh}(+) \\
\mathrm{n}(\%)\end{array}$ & $\begin{array}{c}\mathrm{A} \\
\mathrm{Rh}(-) \\
\mathrm{n}(\%) \\
\end{array}$ & $\begin{array}{c}\mathrm{A} \\
\mathrm{Rh}(+) \\
\mathrm{n}(\%)\end{array}$ & $\begin{array}{c}\mathrm{B} \\
\mathrm{Rh}(-) \\
\mathrm{n}(\%) \\
\end{array}$ & $\begin{array}{c}\mathrm{B} \\
\mathrm{Rh}(+) \\
\mathrm{n}(\%)\end{array}$ & $\begin{array}{c}0 \\
\mathrm{Rh}(-) \\
\mathrm{n}(\%) \\
\end{array}$ & $\begin{array}{c}0 \\
\mathrm{Rh}(+) \\
\mathrm{n}(\%) \\
\end{array}$ & $n$ & p \\
\hline \multirow[t]{2}{*}{ Akciğer } & \multirow{2}{*}{$\begin{array}{l}\text { Erkek } \\
\text { Kadın }\end{array}$} & $4(1.7)$ & $17(7.4)$ & $13(5.7)$ & $91(39.6)$ & $5(2.2)$ & $26(11.3)$ & $13(5.7)$ & $61(26.5)$ & 230 & \multirow[t]{2}{*}{0.680} \\
\hline & & $0(0.0)$ & $0(0.0)$ & $0(0.0)$ & $22(57.9)$ & $1(2.6)$ & $3(7.9)$ & $2(5.3)$ & $10(26.3)$ & 38 & \\
\hline \multirow[t]{2}{*}{ Nazofarenks } & \multirow{2}{*}{$\begin{array}{l}\text { Erkek } \\
\text { Kadın }\end{array}$} & $0(0.0)$ & $6(17.1)$ & $1(2.9)$ & $20(57.1)$ & $0(0.0)$ & $2(5.7)$ & $2(5.7)$ & $4(11.4)$ & 35 & \multirow[t]{2}{*}{0.320} \\
\hline & & $0(0.0)$ & $0(0.0)$ & 1(11.1) & $2(22.2)$ & $0(0.0)$ & 1(11.1) & $0(0.0)$ & $5(55.6)$ & 9 & \\
\hline \multirow[t]{2}{*}{ Beyin } & \multirow{2}{*}{$\begin{array}{l}\text { Erkek } \\
\text { Kadın }\end{array}$} & $0(0.0)$ & $6(15.8)$ & $0(0.0)$ & $13(34.2)$ & $0(0.0)$ & $6(15.8)$ & $0(0.0)$ & \begin{tabular}{|l|}
$13(34.2)$ \\
\end{tabular} & 38 & \multirow[t]{2}{*}{0.299} \\
\hline & & $0(0.0)$ & $0(0.0)$ & $0(0.0)$ & $4(40)$ & $0(0.0)$ & $3(30)$ & $0(0.0)$ & $3(30)$ & 10 & \\
\hline \multirow[t]{2}{*}{ Böbrek } & \multirow{2}{*}{$\begin{array}{l}\text { Erkek } \\
\text { Kadın }\end{array}$} & $0(0.0)$ & $0(0.0)$ & $0(0.0)$ & 41(78.8) & 2(3.8) & $4(7.7)$ & $0(0.0)$ & $5(9.6)$ & 52 & \multirow[t]{2}{*}{0.000} \\
\hline & & $0(0.0)$ & $0(0.0)$ & $0(0.0)$ & $9(42.9)$ & $0(0.0)$ & $0(0.0)$ & 2(9.5) & $10(47.6)$ & 21 & \\
\hline \multirow[t]{2}{*}{ Melanom } & \multirow{2}{*}{$\begin{array}{l}\text { Erkek } \\
\text { Kadın }\end{array}$} & $0(0.0)$ & 2(6.1) & $0(0.0)$ & $13(39.4)$ & $3(9.1)$ & $6(18.2)$ & $0(0.0)$ & $9(27.3)$ & 33 & \multirow[t]{2}{*}{0.496} \\
\hline & & $0(0.0)$ & $0(0.0)$ & $0(0.0)$ & $4(36.4)$ & $3(27.3)$ & $1(9.1)$ & $0(0.0)$ & $3(27.3)$ & 11 & \\
\hline \multirow[t]{2}{*}{ Kan } & \multirow{2}{*}{$\begin{array}{l}\text { Erkek } \\
\text { Kadın }\end{array}$} & $2(5)$ & $5(12.5)$ & $3(7.5)$ & $15(37.5)$ & $0(0.0)$ & $7(17.5)$ & $0(0.0)$ & $8(20)$ & 40 & \multirow[t]{2}{*}{0.004} \\
\hline & & $0(0.0)$ & $0(0.0)$ & $0(0.0)$ & $7(25.9)$ & $2(7.4)$ & $2(7.4)$ & $4(14.8)$ & \begin{tabular}{|l|}
$12(44.4)$ \\
\end{tabular} & 27 & \\
\hline \multirow[t]{2}{*}{ Kolorektal } & \multirow{2}{*}{$\begin{array}{l}\text { Erkek } \\
\text { Kadın }\end{array}$} & $4(1.6)$ & $13(5.2)$ & $12(4.8)$ & 92(36.7) & $5(2)$ & $37(14.7)$ & $6(2.4)$ & $82(32.7)$ & 251 & \multirow[t]{2}{*}{0.001} \\
\hline & & $0(0.0)$ & $9(7.6)$ & $8(6.8)$ & $64(54.2)$ & $0(0.0)$ & $16(13.6)$ & $0(0.0)$ & $21(17.8)$ & 118 & \\
\hline \multirow[t]{2}{*}{ Kontrol } & Erkek & $25(0.8)$ & $514(15.6)$ & $146(4.4)$ & 1272(38.6) & $69(2.1)$ & 478(14.5) & 101(3.1) & 688(20.9) & 3293 & \multirow[t]{2}{*}{0.386} \\
\hline & Kadın & $32(0.9)$ & $505(14.9)$ & $148(4.4)$ & $1365(40.3)$ & $69(2.0)$ & $490(14.5)$ & $74(2.2)$ & 705(20.8) & 3388 & \\
\hline \multirow[t]{2}{*}{ Meme } & Erkek & 1(9.1) & $0(0.0)$ & 2(18.2) & 1(9.1) & $0(0.0)$ & $0(0.0)$ & $0(0.0)$ & $7(63.6)$ & 11 & \multirow[t]{2}{*}{0.006} \\
\hline & Kadın & $12(3.6)$ & $14(4.2)$ & $7(2.1)$ & $149(45)$ & $7(2.1)$ & $52(15.7)$ & $8(2.4)$ & $82(24.8)$ & 331 & \\
\hline \multirow[t]{2}{*}{ Mesane } & Erkek & $0(0.0)$ & 6(33.3) & 2(11.1) & $3(16.7)$ & $0(0.0)$ & $0(0.0)$ & 2(11.1) & $5(27.8)$ & 18 & \multirow[t]{2}{*}{0.001} \\
\hline & Kadın & $0(0.0)$ & $0(0.0)$ & $2(4.3)$ & $28(60.9)$ & $0(0.0)$ & $6(13.0)$ & $3(6.5)$ & $7(15.2)$ & 46 & \\
\hline \multirow[t]{2}{*}{ Mide } & Erkek & $0(0.0)$ & $7(8.9)$ & $0(0.0)$ & $23(29.1)$ & $4(5.1)$ & $7(8.9)$ & $4(5.1)$ & $34(43.0)$ & 79 & 0.000 \\
\hline & Kadın & $0(0.0)$ & $8(7.5)$ & $5(4.7)$ & $65(61.3)$ & 2(1.9) & $4(3.8)$ & 4(3.8) & 18(17.0) & 106 & \\
\hline Özofagus & Erkek & $1(20)$ & $1(20)$ & $0(0.0)$ & $2(40)$ & $0(0.0)$ & $0(0.0)$ & $0(0.0)$ & $1(20)$ & 5 & 0.406 \\
\hline & Kadın & $0(0.0)$ & $1(12.5)$ & $0(0.0)$ & $3(37.5)$ & $0(0.0)$ & $2(25)$ & $0(0.0)$ & $2(25)$ & 8 & \\
\hline Pankreas & Erkek & $0(0.0)$ & $3(8.3)$ & $0(0.0)$ & $12(33.3)$ & $0(0.0)$ & $2(5.6)$ & $5(13.9)$ & 14(38.9) & 36 & 0.669 \\
\hline & Kadın & $0(0.0)$ & $4(16)$ & $0(0.0)$ & $8(32.0)$ & $0(0.0)$ & $3(12)$ & $2(8)$ & $8(32)$ & 25 & \\
\hline Safra.Yolları & Erkek & 2(16.7) & $1(8.3)$ & 1(8.3) & 2(16.7) & $0(0.0)$ & $2(16.7)$ & $4(33.3)$ & $0(0.0)$ & 12 & 0.003 \\
\hline & Kadın & $0(0.0)$ & $0(0.0)$ & $2(8.7)$ & $11(47.8)$ & $0(0.0)$ & $2(8.7)$ & $0(0.0)$ & $8(34.8)$ & 23 & \\
\hline Sarkom & Erkek & $0(0.0)$ & 2(15.4) & $1(7.7)$ & $7(53.8)$ & $0(0.0)$ & $3(23.1)$ & $0(0.0)$ & $0(0.0)$ & 13 & 0.008 \\
\hline & Kadın & $0(0.0)$ & $3(8.8)$ & $1(2.9)$ & $8(23.5)$ & $0(0.0)$ & $2(5.9)$ & $0(0.0)$ & $20(58.8)$ & 34 & \\
\hline
\end{tabular}




\section{F. İnci ve F. Karataş}

O kan grubu (OR, 2.722; \%95 CI: 2.073-3.576, p <0.001) olmak ve yaş artışının (OR, 1.141; \%95 CI: $1.134-1.148, \mathrm{p}<0.001)$ kanser hastalı̆̆ 1 için bağımsiz prediktif faktörler olduğu bulundu (Tablo IV).

Tablo IV. Çok değişkenli lojistik regresyon analizi

\begin{tabular}{|l|l|l|l|}
\hline \multicolumn{1}{|c|}{ Değişkenler } & \multicolumn{1}{|c|}{ OR } & \multicolumn{1}{c|}{$95 \% \mathrm{Cl}$} & \multicolumn{1}{c|}{$\mathrm{p}$} \\
\hline A Grubu & 2.415 & $1.869-3.120$ & 0.000 \\
\hline B Grubu & 0.508 & $0.376-0.686$ & 0.000 \\
\hline O Grubu & 2.722 & $2.073-3.576$ & 0.000 \\
\hline Yaş & 1.141 & $1.134-1.148$ & 0.000 \\
\hline $\begin{array}{l}\text { p,regresyon analizi Yaş, Cinsiyet, Rh, Kan grubu değişkenlerini içerir; OR, } \\
\text { Odds Ratio; Cl, Confidence Interval }\end{array}$
\end{tabular}

\section{Tartışma ve Sonuç}

Çalışmamıza katılan tüm bireylerin kan grubu dağılımlarının, Eren'in 2019 yılında İstanbul ili kan merkezi verileri ile yapmış olduğu toplam 123.900 bireyin kan grubu analizini içeren çalışma sonuçları ile benzer olduğu görüldü ${ }^{7}$. Yine 2015 yllındaki Salduz ve arkadaşları tarafından yapılan çalışmadaki İstanbul ili kan grubu dağılım sonuçları çalışmamızdaki sonuçlar ile $(\mathrm{A}>\mathrm{O}>\mathrm{B}>\mathrm{AB})$ benzerdi $^{8}$.

Aird'in A kan grubunun mide kanserinde önemli bir yere sahip olduğunu yayınlaması sonrasında diğer kanser tiplerinin etiyolojisinde kan gruplarının rolü araştırılmıştır ${ }^{9}$. Sonraki çalışmalarda da, kan gruplarının çeşitli kanserler için bir risk oluşturduğu bildirmiş$\operatorname{tir}^{10}$. Bizim sonuçlarımızda da kanser hastaları ile kontrol grubunun $\mathrm{ABO}$ ve $\mathrm{Rh}$ sonuçları arasında anlamlı farkl111klar bulundu. Yine kanser hastaları alt tipleri arasında da bu anlamlı farklılıklar görüldü. Tüm grupta Rh faktörü değerlendirildiğinde \%10.7 Rh (-) ve \%89.3 Rh (+) birey vardı. Daha önce yapılan çalışmalarda $\mathrm{Rh}(+)$ kan grubu oranlarının bölgeden bölgeye değișmekle birlikte \%10-15 arasında olduğu bildirilmiştir ${ }^{11}$. Çalışmamızda, kanser ve kontrol grupları arasında $\mathrm{Rh}$ faktörü kıyaslandığında $(p=0.294)$ anlamlı farklılık bulunmadı. Rh faktörü ile ilgili olarak literatürde birbirine zıt sonuçlar bulunmaktadır. Ronco ve arkadaşlarının çalışmasında ${ }^{12}$ farklılık varken, Oral ve arkadaşlarının çalışmasında fark bulunamamıştır ${ }^{13}$.

Çalışmamızda hem literatüre benzer hem de farklı sonuçlar elde edilmiştir. Kanser alt tipleri sırasıyla ele alındığında akciğer kanserli hastalarda A kan grubunun diğer gruplarına oranla daha fazla olduğu görüldü. Roots ve arkadaşlarının çalışmasında A kan grubu sıklığının akciğer kanseri hastalarında kontrol grubuna kıyasla anlamlı derecede yüksek olduğu gösterilmiştir ${ }^{14}$. Diğer bir çalışmada ise akciğer kanseri olan hastalar ile kontrol grubu arasında $\mathrm{ABO}$ kan grupları ve $\mathrm{Rh}$ faktör dağılımı açısından anlamlı fark bulunamamıştır ${ }^{15}$.
Çalışmamızda böbrek tümörlü hastalarda anlamlı olarak ( $\mathrm{p}=0.001)$ A Rh (+) kan grubunun daha yüksek olduğu görüldü. Ko ve arkadaşlarının çalışmasında böbrek tümörlü hastalarda A kan grubunun yüksek oranda bulunduğu, ayrıca olumlu prognoz için bağımsız prediktif faktör olduğu vurgulanmıştır ${ }^{16}$. Aksine ABO kan grubunun prostat, mesane ve böbrek kanseri ile ilişkisini değerlendirmek amacıyla yapılmış başka bir çalışmada ise, böbrek kanseri hastalarında ABO kan grupları için bir farklılık bildirilmemiştir ${ }^{17}$. Prostat kanseri ve mesane kanseri hastalarında veriler, önemli ölçüde daha yüksek bir B kan grubu varlığını göstermiştir $^{17}$. Klatte ve arkadaşlarının çalışmasında mesane kanserli hastalarda daha fazla oranda A kan grubu tespit edilmiştir ${ }^{18}$. Çalışma sonuçlarımızda ise mesane kanseri için anlamlı fark bulunamadı. Prostat kanserli hastalarımızın sonuçları değerlendirildiğinde, Markt ve arkadaşlarının yaptığı çalışmada olduğu gibi ABO kan grupları arasında bir farklılık bulunamadı ${ }^{19}$. Çalışmamız sonuçlarına benzer şekilde, malign melanomda Chan ve arkadaşları ABO grupları arasında A kan grubu lehine anlamlı farklılık tespit etmişlerdir ${ }^{20}$. Çalışmamızda uterus kanseri ve ABO kan grubu arasında anlamlı farklılık bulunmamasına rağmen literatürde A kan grubunun diğer gruplara göre daha sık ortaya çıktığı tespit edilmiştir ${ }^{21}$. Over kanseri ile kan grubu ilişkisine bakıldığında $(\mathrm{p}=0.033)$ A kan grubu lehine anlamlı fark bulundu. Benzer şekilde iki çalışmada A kan grubu ile over kanseri arasında istatistiksel olarak anlamlı ilişki olduğu gösterilmiştir ${ }^{21,22}$. Yakın zamanda yapılan bir çalışmada, 49.153 kadın arasında $\mathrm{ABO}$ kan grubu ile over kanseri arasındaki ilişki incelenmiş ve B kan grubu ile over kanseri arasında olası bir ilişki olduğu öne sürülmüştür ${ }^{23}$. Kolorektal kanserlerin ABO kan grubu ilişkisini inceleyen Kahramanca ve arkadaşları, A Rh (+) kan grubunun risk faktörü olabileceğini bildirmişlerdir ${ }^{24}$. Çalışmamızda ( $\mathrm{p}=0.042)$ anlamlılık düzeyinde A Rh (+) kan grubu lehine fark bulundu. Aksine Khalili ve arkadaşları ABO kan grubu ile kolorektal kanser arasındaki ilişkiyi araştırmış ve anlamlı bir fark olmadığını bildirmiştir ${ }^{25}$.

Meme kanserinin ABO kan grubu ile ilişkisini inceleyen Stamatakos ve arkadaşlarının çalışmasında A kan grubunda meme kanseri görülme oranı yüksek bulunmuştur $^{26}$. Sexana ve arkadaşları bu çalışmaya benzer şekilde A kan grubunda meme kanseri oranını yüksek bulurken, Flavarjani ve arkadaşları herhangi bir ilişki bulamamıştır ${ }^{10,27}$. 14 çalışmayı içeren bir metaanalizde A kan grubuna sahip bireylerin daha yüksek oranda meme kanseri riskine sahip olabileceği ileri sürülmüştür ${ }^{28}$. Başka bir çalışmada ise B kan grubunda, meme kanseri insidansı artışının sınırda anlamlı olduğu bulunmuştur ${ }^{29}$. Çalışmamızda, A kan grubu lehine ( $\mathrm{p}<0.001)$ anlamlı fark olduğu tespit edildi.

Literatürde özofagus kanseri ve ABO kan grubu ilişkisi ile ilgili çelişkili sonuçlar olsa da bazı çalışmalar B 


\section{Kan Grubu ve Kanser İlişkisi}

kan grubu ve A kan grubu ile ilişkilendirilmiştir ${ }^{30,31}$. Bizim çalışmamızda ise özefagus kanseri için anlamlı bir fark bulunamadı. Çalışmamızda mide kanserli hastalarda ABO kan grubu ile istatistiksel anlamlı bir fark bulunamasa da $(\mathrm{p}=0.068)$ numerik olarak yüksek oranda (\%47.6) A kan grubunun olduğu belirlendi. Kan grubu ve kanser ilişkisini ilk inceleyen Arid tarafindan gastrik kanserle A kan grubu arasında ilişki bildirilmiştir ${ }^{9}$. Bundan sonraki yapılan bir çok çalışmada gastrik kanser ve A kan grubu ilişkisi gösterilmiştir $^{32,33}$.

Safra yolları tümörleri için sonuçlarımız değerlendirildiğinde anlamlı bir fark bulamadık. Pandey ve arkadaşları A ve AB kan gruplarının; safra kesesi kanseri riskinde artış ile korele olduğunu bildirmişlerdir ${ }^{34}$. Çalışmamızda pankreas kanseri ile ilgili literatürden farklı olarak O kan grubunun hastalarımızda anlamlı olarak ( $p=0.005)$ fazla olduğu görüldü. Çalışmalarda A kan grubunda pankreas kanserinin daha fazla olduğu O kan grubunun ise prognoz açısından daha kötü seyrettiği görülmüştür ${ }^{35,36}$. Çalışmamızda, sarkom başlığı altındaki tümörler değerlendirildiğinde anlamlı fark bulunamadı. Yapar ve arkadaşlarının yaptığı çalışmada malign yumuşak doku sarkomları ile ABO ve Rh kan grubu arasında anlamlı bir ilişki saptanmamıştır $^{37}$. Testis tümörlü hastalar değerlendirildiğinde A Rh (+) olan bireylerde testis kanserinin daha fazla olduğu görülmekle birlikte çalışmamızda anlamlı farklılık bulunamadı. Yakın zamanda Güner ve arkadaşlarının yaptığı bir çalışmada bizim elde etmiş olduğumuz verilere benzer sonuçlar bildirmişlerdir ${ }^{38}$. Çalışmamızda, beyin tümörlü hastalar değerlendirildiğinde ABO kan grupları arasında anlamlı fark olmad1ğ1, A ve B kan gruplarının numerik olarak fazla olduğu görüldü. 2017 yılında Allouh ve arkadaşlarının yaptığı çalışmada benzer şekilde A kan grubunda glioblastom gelişme riskinin daha fazla olduğu bulunmuştur ${ }^{39}$. Çalışmamızda, hematolojik tümörler değerlendirildiğinde ABO kan grupları arasında anlamlı fark görülmedi. Daha önceki çalışmalarda akut lenfoblastik lenfoma hastalarında $\mathrm{AB}$ kan grubunun yüksek olduğu bildirilirken ${ }^{40}$, başka bir çalışmada ise kronik lenfositik lösemi hastalarında A kan grubunun diğer gruplara göre fazla oranda olduğu görülmüştür ${ }^{41}$.

Yukarıdaki bilgiler ışığında çoklu regresyon analizi sonuçlarımızla uyumlu olarak özellikle A ve O kan grubuna sahip olmak kanser gelişimi için prediktif faktör olduğu görüldü. Ayrıca literatürle uyumlu olarak yaşın da kanser gelişiminde önemli bir faktör olduğu görüldü ${ }^{42,43}$. Bu sonuçların kanser gelişimine neden olabilecek diğer faktörlerin varlığına göre değişebileceği göz önünde bulundurularak değerlendirilmesi gerekir.

Çalışmamızın bazı limitasyonları mevcuttur. Öncelikle kanser hasta sayımız ve bazı alt tipleri sinırlı say1dadır. Bir diğeri ise kanser hastalarında sigara, alkol, genetik faktörler, çevresel faktörler ve yaşam tarzı değişiklikleri gibi verilerin net olmaması nedeniyle analizde bu faktörlerin kanser gelişimine katkısı değerlendirilememiştir. İleride tüm bu verilerin dahil edildiği analizlerin yapılacağı, çok merkezli ve daha çok hasta sayısı içeren çalışmalara ihtiyaç vardır.

Sonuç olarak, kanser hastaları ve kontrol grubunda ABO-Rh kan gruplarının dağılımında istatistiksel anlamlı farklılık bulundu. Pankreas kanserinde O kan grubu, malign melanom ve böbrek tümörlerinde ise A kan grubu daha yüksek oranda tespit edildi. Yaş, A ve O kan gruplarının kanser için prediktif faktörler olduğu görüldü. Sonuçlarımız literatüre benzer bulgular içermektedir. $\mathrm{Bu}$ durum bazı kanser türleri ile kan grupları arasında bir ilişki olduğunu gösteren daha önce yapılmış çalışmaları destekler niteliktedir. Bu nedenle kan gruplarının kanser etyopatogenezinde ne gibi bir rolü olduğu konusunda detaylı moleküler ve genetik temelli çalışmalara ihtiyaç vardır.

\section{Etik Kurul Onay Bilgisi:}

Onaylayan Kurul: Karabük Üniversitesi Girişimsel Olmayan

Klinik Araştırmalar Etik Kurulu

Onay Tarihi: 09.06.2020

Karar No: 2020/250

\section{Kaynaklar}

1. Jemal, A., et al., Global cancer statistics. CA: a cancer journal for clinicians, 2011. 61(2): p. 69-90.

2. Franchini, M., G.M. Liumbruno, and G. Lippi, The prognostic value of ABO blood group in cancer patients. Blood Transfusion, 2016. 14(5): p. 434.

3. Huang, J.Y., et al., ABO blood type and the risk of cancerFindings from the Shanghai Cohort Study. PloS one, 2017. 12(9): p. e0184295.

4. Aird, I., H.H. Bentall, and J.F. Roberts, Relationship between cancer of stomach and the ABO blood groups. British medical journal, 1953. 1(4814): p. 799

5. Amundadottir, L., et al., Genome-wide association study identifies variants in the ABO locus associated with susceptibility to pancreatic cancer. Nature genetics, 2009. 41(9): p. 986-990.

6. Li, B., et al., Association between the ABO blood group and risk of common cancers. Journal of evidence-based medicine, 2014. 7(2): p. 79-83.

7. Eren, C., İstanbul İlinde $\mathrm{ABO}$ ve Rh Kan Grupları Dağılımının Analizi. Dicle Medical Journal/Dicle Tip Dergisi, 2019. 46(2).

8. Salduz, Z.I.Y., et al., ABO and Rh blood group distribution in Istanbul Province (Turkey). İstanbul Med J, 2015. 16: p. 98-100.

9. Aird, I., et al., The blood groups in relation to peptic ulceration and carcinoma of colon, rectum, breast, and bronchus. British Medical Journal, 1954. 2(4883): p. 315.

10. Saxena, S., et al., Association of ABO blood group and breast cancer in Jodhpur. Indian J Physiol Pharmacol, 2015. 59(1): p. 63-68.

11. Özkasap, S., et al., Analysis of $\mathrm{ABO}$ and $\mathrm{Rh}$ blood groups distribution in East Karadeniz region of Turkey. Dicle Med J, 2013. 40(1): p. 100-104

12. Ronco, A.L., et al., Rh factor, family history and risk of breast cancer: A case-control study in Uruguay. Cancer Detection and Prevention, 2009. 32(4): p. 277-285.

13. Oral, A. and T. Sahin, Prognostic role of ABO blood group and Rhesus factor in cirrhotic patients with hepatocellular carcinoma. Scientific Reports, 2019. 9(1): p. 1-6.

14. Roots, I., et al., Debrisoquine hydroxylation phenotype, acetylation phenotype, and $\mathrm{ABO}$ blood groups as genetic host factors 


\section{F. İnci ve F. Karataş}

of lung cancer risk. Klin Wochenschr, 1988. 66(Suppl 11): p. 87-97.

15. Oguz, A., et al., Lack of any association between blood groups and lung cancer, independent of histology. Asian Pac J Cancer Prev, 2013. 14(1): p. 453-6.

16. Ko, K., et al., Prognostic significance of blood type A in patients with renal cell carcinoma. Urology journal, 2016. 13(4): p. 2765-2772.

17. Stakišaitis, D., et al., ABO blood group polymorphism has an impact on prostate, kidney and bladder cancer in association with longevity. Oncology letters, 2018. 16(1): p. 1321-1331.

18. Klatte, T., et al., Impact of ABO blood type on outcomes in patients with primary nonmuscle invasive bladder cancer. The Journal of urology, 2014. 191(5): p. 1238-1243.

19. Markt, S.C., et al., ABO blood group alleles and prostate cancer risk: results from the breast and prostate cancer cohort consortium (BPC3). The Prostate, 2015. 75(15): p. 1677-1681.

20. Chang, L., et al., Incidence and metastasis of cutaneous malignant melanoma with respect to $\mathrm{ABO}$ blood groups: a casecontrolled study in northeast of China. PloS one, 2014. 9(2): p. e88096.

21. Marinaccio, M., et al., Blood groups of the $\mathrm{ABO}$ system and survival rate in gynecologic tumors. Minerva ginecologica, 1995. 47(3): p. 69-76.

22. Henderson, J., V. Seagroatt, and M. Goldacre, Ovarian cancer and $\mathrm{ABO}$ blood groups. Journal of Epidemiology \& Community Health, 1993. 47(4): p. 287-289.

23. Gates, M.A., et al., ABO blood group and incidence of epithelial ovarian cancer. International journal of cancer, 2011. 128(2): p. 482-486.

24. Kahramanca, Ş., et al., Kolorektal Kanserlerde Kan Grubu Özellikleri. Turkish Journal of Colorectal Disease, 2018. 28(2): p. 76.

25. Khalili, H., et al., ABO blood group and risk of colorectal cancer. Cancer Epidemiology and Prevention Biomarkers, 2011. 20(5): p. 1017-1020.

26. Stamatakos, M., et al. Breast cancer incidence in Greek women in relation to ABO blood groups and Rh factor. in International seminars in surgical oncology. 2009. Springer.

27. Flavarjani, A.H.M., et al., Study of the association between blood types and breast cancer among Isfahanian women with breast cancer. Advanced Biomedical Research, 2014. 3.

28. Miao, S.Y., et al., Influence of ABO blood group and $\mathrm{R}$ hesus factor on breast cancer risk: A meta-analysis of 9665 breast cancer patients and 244768 controls. Asia-Pacific Journal of Clinical Oncology, 2014. 10(2): p. 101-108.
29. DIXIT, R., et al., Epıdemılogical Study Of Breast Cancer Patients And Their Association With Abo Blood Group.

30. Su, M., et al., Relationship between ABO blood groups and carcinoma of esophagus and cardia in Chaoshan inhabitants of China. World journal of gastroenterology, 2001. 7(5): p. 657.

31. Singh, K., et al., Relative risk of various head and neck cancers among different blood groups: an analytical study. Journal of clinical and diagnostic research: JCDR, 2014. 8(4): p. ZC25.

32. Yu, H., et al., Association of ABO Blood Groups and Risk of Gastric Cancer. Scandinavian Journal of Surgery, 2019: p. 1457496919863886.

33. Edgren, G., et al., Risk of gastric cancer and peptic ulcers in relation to ABO blood type: a cohort study. American journal of epidemiology, 2010. 172(11): p. 1280-1285.

34. Pandey, M., A. Gautam, and V. Shukla, ABO and Rh blood groups in patients with cholelithiasis and carcinoma of the gall bladder. BMJ, 1995. 310(6995): p. 1639.

35. Engin, H., et al., ABO blood group and risk of pancreatic cancer in a Turkish population in Western Blacksea region. Asian pacific journal of cancer prevention, 2012. 13(1): p. 131133.

36. Wolpin, B.M., et al., ABO blood group and the risk of pancreatic cancer. Journal of the National Cancer Institute, 2009. 101(6): p. 424-431.

37. Yapar, A. and F.C. Sökmen, The Relationship between AB0 Blood Group and Malignant Soft-Tissue Sarcomas AB0 Kan Grubu ve Malign Yumuşak Doku Sarkomları Arasındaki İlişki.

38. Güner, S.İ. and E. Güner, ABO Blood Types and Risk of Testicular Cancer in Turkish Population: Preliminary Results. Bull Urooncol, 2019. 18: p. 135-137.

39. Allouh, M.Z., et al., Glioblastoma and ABO blood groups: further evidence of an association between the distribution of blood group antigens and brain tumours. Blood Transfusion, 2017. 15(6): p. 543.

40. Tavasolian, F., et al., Relationship between ABO blood group and Acute Lymphoblastic Leukemia. Iranian journal of pediatric hematology and oncology, 2014. 4(1): p. 1.

41. Janardhana, V., D.N. Propert, and R.E. Green, ABO blood groups in hematologic malignancies. Cancer genetics and cytogenetics, 1991. 51(1): p. 113-120.

42. Ershler, W.B. and D.L. Longo, Aging and Cancer: Issues of Basic and Clinical Science. JNCI: Journal of the National Cancer Institute, 1997. 89(20): p. 1489-1497.

43. SMETANA, K., et al., Ageing as an important risk factor for cancer. Anticancer research, 2016. 36(10): p. 5009-5017. 